\title{
Política externa independente e a institucionalização das atividades espaciais no Brasil: histórias cruzadas
}

\author{
Independent Foreign Policy and the institutionalization \\ of space activities in Brazil: intersecting stories
}

DOI: $10.21530 /$ ci.v12n2.2017.660

Renata Corrêa Ribeiro ${ }^{1}$

\section{Resumo}

O primeiro país a se lançar ao cosmos foi a União Soviética, ao lançar o satélite Sputnik I, em 1957. A partir de então, o espaço se tornou a nova fronteira para a projeção de prestígio nacional e poderio dos Estados, principalmente EUA e URSS. Posteriormente, diversas nações desenvolveram a tecnologia e passaram a disputar com as duas superpotências o domínio da ciência e do acesso ao espaço. O Brasil foi um dos pioneiros, entre os países em desenvolvimento, a se inclinar para as ciências espaciais. Em 1961, ainda durante o governo de Jânio Quadros, o programa espacial brasileiro começou a tomar uma forma institucionalizada, com a preocupação com a formação de cientistas e o estabelecimento de uma infraestrutura física com institutos de pesquisa e centros de lançamento. Questiona-se, no entanto, o motivo pelo qual as atividades espaciais terem sido iniciadas no Brasil em 1961. O objetivo deste artigo é, portanto, apresentar as razões que levaram à institucionalização das atividades espaciais durante a curta gestão de Jânio Quadros, a partir da criação do GOCNAE, em 1961. Argumenta-se que o caráter arrojado da política externa instituída por esse presidente, a chamada "Política Externa Independente”, possibilitou uma atuação mais pragmática em relação às ciências espaciais.

Palavras-chave: Programa Espacial Brasileiro; Política Espacial; Política Externa Independente; PEI; Jânio Quadros; Yuri Gagarin; GOCNAE

\footnotetext{
Abstract

The first country to enter the Space Age was the Soviet Union (USSR), when it launched the Sputnik I satellite in October 1957. Thereafter, space became the new frontier for projecting the United States and Soviet Union's prestige and power. Subsequently, many nations started

1 Instituto de Relações Internacionais da Universidade de Brasília, em Brasília/DF, Brasil. E-mail: renata.cori@gmail.com. Artigo submetido em 27/03/2017 e aprovado em 24/08/2017.
} 
developing space technology and to challenge both superpowers in the control of space science and in the access to the outer space. Brazil was one of the first developing countries to lean towards the space sciences. In 1961, during Jânio Quadros's term, Brazilian space program took an institutionalized form, as the concern about scientists' formation and a physical infrastructure's deployment with research centers and launch sites showcase. However, the most frequent question is why the space activities started in Brazil in 1961. Therefore, the aim of this article is presenting the reasons that lead to the institutionalization of space activities during Janio Quadros' term, by creating GOCNAE. One of the main arguments is that the audacious nature of its foreign policy, the Independent Foreign Policy, enabled a more pragmatic behavior with regard to the space sciences.

Keywords: Brazilian Space Program; Space Policy; Independent Foreign Policy; IFP; Jânio Quadros; Yuri Gagarin; GOCNAE

\section{Introdução}

No dia 4 de outubro de 1957, a União Soviética (URSS) apresentou seu pioneirismo em assuntos do espaço exterior ao pôr em órbita o primeiro satélite artificial do mundo, o Sputnik I. Quatro anos mais tarde, novamente a URSS impactou o mundo ao enviar Yuri Gagarin ao espaço, a bordo da nave Vostok. Os dois acontecimentos deram início à Era Espacial, impulsionada, principalmente, pelo clima de competição entre as duas superpotências da época, Estados Unidos (EUA) e União Soviética.

O Brasil foi um dos primeiros países em desenvolvimento a se entusiasmar pelas ciências espaciais. As notícias que chegavam da URSS e dos EUA ajudaram a projetar um pequeno grupo de brasileiros interessados em desenvolver pesquisas e tecnologias espaciais no país. O grupo ganhou prestígio e acabou influenciando fortemente o presidente Jânio Quadros a criar a primeira instituição oficial brasileira encarregada de estruturar o órgão que cuidaria dos assuntos referentes ao espaço, o Grupo de Organização da Comissão Nacional de Atividades Espaciais (GOCNAE), instituído pelo Decreto n. 51.133, de 3 de agosto de 1961.

A postura decisiva de Quadros nessa matéria foi influenciada, sobretudo, pela adoção de uma nova forma de fazer política externa no Brasil: a Política Externa Independente (PEI), iniciada por Jânio Quadros e Afonso Arinos, seu chanceler. As diretrizes básicas da PEI permitiam uma maior abertura das relações do Brasil com os países do mundo, a despeito de suas opções ideológicas e vinculações 
políticas. Nesse sentido, houve uma tentativa de conduzir o Brasil à sua posição de direito no jogo das grandes nações².

Para alcançar seu intento, Jânio Quadros convenceu-se que desenvolver as ciências espaciais internamente traria grandes benefícios ao país. A articulação com civis e militares brasileiros interessados nas atividades espaciais deu início a um rápido processo que culminou na publicação do decreto de criação do GOCNAE. A visita ao Brasil do soviético Yuri Gagarin, primeiro homem a ir ao espaço, entre 29 de julho e 2 de agosto do mesmo ano, teve, também, um grande peso na decisão do presidente da República. A sua importância pode ser comprovada em diversas correspondências e jornais da época.

O objetivo deste artigo é, portanto, demonstrar como a institucionalização das atividades espaciais no Brasil está intimamente ligada à nova forma de fazer política externa formulada por Jânio Quadros, a Política Externa Independente (PEI). Argumenta-se que o caráter arrojado de sua política externa possibilitou uma atuação mais pragmática em relação às ciências espaciais. Em menos de sete meses, Quadros recebeu conselhos de especialistas na área espacial, recepcionou Gagarin no Brasil e publicou decreto que instituía o grupo de organização da comissão responsável pelas atividades espaciais.

Para isso, a autora optou pelo seguinte arranjo para apresentar o problema de pesquisa: na primeira seção, será feita uma apresentação das diretrizes gerais da PEI, formuladas durante a gestão Quadros-Arinos, dando enfoque nas razões de sua criação; a segunda seção será responsável por fazer um resgate histórico dos eventos e instituições que abriram caminho para a institucionalização das atividades espaciais no início dos anos 1960; e, por fim, a terceira seção apresentará os fatos e motivos que levaram o presidente Jânio Quadros a tomar tal atitude.

\section{O caráter arrojado da Política Externa Independente de Jânio Quadros}

Em sua curta gestão como Presidente (exatamente seis meses e 6 dias $^{3}$ ), Jânio Quadros inaugurou o conjunto de iniciativas de uma nova vertente de política

2 O trecho do artigo de Jânio, publicado na Foreign Affairs de 1961, demonstra isso: "Interesse demonstrado na posição do Brasil em assuntos internacionais é, em si mesmo, uma prova da presença de uma nova força no cenário mundial [...] Somos uma nação de proporções continentais, ocupando quase a metade da América do Sul [...] Dentro da próxima década nossa população atingirá perto de cem milhões de habitantes e a rápida industrialização de algumas regiões do país faz prever a nossa transformação em uma potência econômica [...] Se somente agora o Brasil está sendo ouvido em assuntos internacionais, é porque, ao assumir o poder, resolvi tirar proveito das consequências da posição que atingimos como nação” (QUADROS, 1961, p.1).

3 Jânio Quadros governou o Brasil de 31 de janeiro de 1961 a 25 de agosto de 1961. 
externa que, posteriormente, foi sistematizada e aprofundada por San Tiago Dantas (Ministro das Relações Exteriores do presidente João Goulart), que a batizou de “Política Externa Independente”. Apesar de não representar uma inovação completa, pois apenas continuava e aprofundava uma política externa mais autônoma iniciada em Vargas, como afirmou Visentini (2009), ela apresentava um conjunto de noções e atitudes independentes e articuladas, além de ter um conteúdo mais sistêmico.

Tanto Visentini (2009, p. 123) quanto Álvares (1989, p. 58-59) concordam que as razões para o caráter arrojado da política externa de Jânio Quadros encontram suas origens em circunstâncias internas e externas. Internamente, o país havia passado por uma grande transformação, tanto econômica quanto socialmente. O êxodo rural atingiu seu auge, deslocando enormes contingentes populacionais para as cidades; o setor industrial (fortemente estimulado pelo Plano de Metas de Juscelino Kubitschek) ultrapassou o setor agrícola em valor e importância econômica para o país; o mercado interno se ampliou, assim como se intensificaram as desigualdades sociais e regionais. Tudo isso levou o país a uma crise socioeconômica preocupante (VISENTINI, 2009, p. 124; ÁlVARES, 1989, p. 58-59).

A diminuição dos preços dos produtos primários exportados pelo Brasil foi o grande vilão da economia naquele momento. Com o desequilíbrio da balança comercial, as divisas atingiram um nível extremamente baixo, enquanto as remessas de lucros para o exterior só cresciam. Somado a isso, a sociedade convivia com alto desemprego, alta inflação e a baixa de salários. Assim, apesar da extraordinária transformação ocorrida na economia nos anos de Kubitschek, sabia-se que ainda havia uma forte dependência externa. O próprio Jânio Quadros, em seu artigo na Foreign Affairs, deixou transparecer sua insatisfação com o jogo que as grandes potências ainda faziam com as nações em desenvolvimento ${ }^{4}$.

A nova política externa era uma tentativa de reverter o quadro desfavorável enfrentado pelo Brasil internamente. Visentini (2009, p. 126) observa que entre as bases internas da PEI estavam a articulação de um projeto de desenvolvimento comum para enfrentar a crise vivida somada às necessidades externas do país, que geravam estagnação econômica (exportação dos produtos primários, obtenção de divisas para importação de bens de capital, investimentos em tecnologias estrangeiras etc.).

4 "Não estamos em posição de permitir a liberdade de ação de forças econômicas em nosso território, simplesmente porque essas forças, controladas do exterior, fazem o seu próprio jogo e não o de nosso país” (QUADROS, 1961, p. 5). 
A forte dependência do Brasil suscitava uma mudança imperiosa na política externa, que tinha a função de corrigir os numerosos desequilíbrios econômicos, que tem na balança de pagamentos um dos maiores exemplos. Nesse sentido, a ampliação de mercados para as exportações brasileiras torna-se essencial para conter as instabilidades econômicas e a diversificação de parcerias, um dos alicerces da nova política externa gestada por Quadros.

Para Wrobel (1993, p. 195), as mudanças introduzidas pela dupla QuadroArinos previam meios de se obter o desenvolvimento mais rapidamente. A forma encontrada para se alcançar esse intento foi utilizar uma postura mais agressiva na conquista de novos mercados e na ampliação das relações comerciais com o resto do mundo. Após décadas de forte dependência do mercado norte-americano, a nova gestão optou por restabelecer relações diplomáticas e comerciais com países que apresentavam a possibilidade de absorver os principais produtos exportados pelo Brasil.

Tudo isso só foi possível devido à conjunção com fatores externos. A URSS dos anos 1960 havia se transformado, dominando a posição de potência econômica e tecnológica, como o lançamento do primeiro satélite artificial da Terra, o Sputnik I, em 1957, havia confirmado. Assim, as possibilidades de cooperação financeira, comercial e tecnológicas com os países socialistas se tornaram um grande atrativo para um país enfrentando uma forte crise socioeconômica, como era o caso do Brasil. Além disso, em 1957, o Tratado de Roma cria a Comunidade Econômica Europeia (CEE), que dá preferências para os seis países integrantes do bloco (França, Alemanha, Holanda, Itália, Luxemburgo e Bélgica), não extensiva aos países de fora. Como consequência, o Brasil enfrenta problemas para exportar para esse continente, que se somava às dificuldades para exportar café para os EUA, já que os dois países não entram em um acordo acerca do preço do produto.

Outra alteração importante no contexto internacional era a emergência de um bloco organizado de países do Terceiro Mundo. A aceleração das descolonizações dos países da África e Ásia deu lugar à união dos países terceiro-mundistas na busca de ideais comuns, como o neutralismo, o afroasiatismo e criação de uma nova ordem mundial, como ficou claro durante a Conferência dos Países Não Alinhados, em 1961 (VISENTINI, 2009, p. 129). Apesar de não participar como membro desse movimento ${ }^{5}$, o Brasil percebia que a ascensão de novos Estados no

5 O Brasil apenas participou como observador enviando o diplomata João Augusto de Araújo Castro. Ele compareceu à Reunião Preliminar e à Conferência de Chefes de Estado e de Governo dos Países Não Alinhados, realizada no Cairo, entre 5 e 13 de julho de 1961 (CERVO; BUENO, 2010, p. 326). 
cenário mundial alterava a configuração das relações internacionais. Acreditava-se que havia uma tendência de se materializar uma nova ordem econômica, política e social de inclusão dos países do Terceiro Mundo nos processos decisórios mundiais.

Após longa reflexão a respeito das conjunturas interna e externa, Jânio Quadros e Afonso Arinos articulam as bases da política externa a ser seguida durante a sua gestão. Na mensagem presidencial enviada ao Congresso Nacional, em 20 de março de 1961, Quadros explicitou as 15 diretrizes gerais e regionais de sua política externa (FRANCO, 2007, p. 49). Cervo (1998, p. 70), no entanto, sintetizou-a em quatro pontos principais: 1) o abandono da subserviência aos interesses estrangeiros e a busca dos interesses nacionais que levam ao desenvolvimento do país; 2) aproximação de outras nações recém-emancipadas da África e Ásia, assim como da América Latina, para se construir uma frente contra as desigualdades entre as nações; 3 ) inauguração de um pan-americanismo de conteúdo econômico e social, superando a fase política e ideológica; 4) a liberdade de o Brasil não se vincular a nenhum bloco ou ideologia, mantendo-se neutro na Guerra Fria, mantendo relações diplomáticas e comerciais com todas as nações do mundo, a despeito de sua vinculação ideológica.

Nesse sentido, depreende-se que Jânio Quadros usava a política externa como instrumento a serviço da resolução de problemas internos (CERVO; BUENO, 2010, p. 327). A liberalidade da política de Quadros possibilitou uma aproximação com a URSS e outros países socialistas. O objetivo, contudo, era retirar dessas relações somente aquilo que poderia ser positivo ao Brasil. E essa relação de pragmatismo pode ser comprovada na área das ciências. Entusiasmado com o pioneirismo soviético na área espacial - como mostrou o lançamento do Sputnik I -, Quadros convenceu-se de que não podia deixar de se aproximar daquele país, que poderia trazer muitos dividendos para o Brasil nessa seara. A recepção de Yuri Gagarin faz parte dessa rede de esforços, estimulada pelo presidente da República, para se institucionalizar as atividades espaciais no país. Ela, no entanto, não seria possível sem o caráter arrojado da sua forma de fazer política externa.

\section{A origem das atividades espaciais no Brasil}

O processo de institucionalização das atividades no Brasil relaciona-se com o entusiasmo de uma pequena, mas dedicada comunidade científica brasileira, que trabalhava arduamente pelo progresso científico e tecnológico do país desde 
os anos de 1930. A inserção do Brasil nesse novo campo esteve ligada, no início, à pesquisa e ao desenvolvimento no ramo da energia nuclear. Como aponta Sato (2013, p. 815), a comunidade científica brasileira preocupava-se em “integrar-se aos avanços em curso na ciência no mundo, e a capacitação na área de energia nuclear se afigurava como algo de importância primordial”.

Especificamente no campo das aplicações espaciais, o interesse do Brasil surgiu dentro de instituições militares, de forma similar à grande parte de outros países. Em 1941, com a criação do Ministério da Aeronáutica, em meio à Segunda Guerra Mundial, o Brasil também pôde iniciar sua caminhada que, nesse primeiro momento, visava apenas a fundação de um centro de pesquisas capaz de desenvolver tecnologias militares.

Quando se iniciaram as hostilidades que culminaram na Segunda Guerra Mundial (1939-1945), o governo de Getúlio Vargas declarou sua neutralidade, apesar de essa neutralidade ter sido violada diversas vezes em função da incapacidade militar brasileira em vigiar seu litoral (CERVO; BUENO, 2010, p. 249). O interesse norte-americano em aproximar-se do país para obter vantagens da posição geográfica brasileira e de seus minerais estratégicos estimulou o início de um programa de aproximação aeronáutica. Diversos militares brasileiros foram enviados a instituições de renome estadunidenses para consolidarem seu aprendizado e incorporarem novos conhecimentos ao país, que assistia atento aos desdobramentos da guerra.

A interação entre militares brasileiros e norte-americanos - principalmente no front, após a declaração de guerra do Brasil contra o Eixo, em 1942, que enviou tropas para lutar ao lado dos Aliados no norte da África - somada à falta de capacidade militar do país levaram a reflexões acerca dos principais gargalos que impediam o Brasil de atingir seus objetivos militares: a necessidade de criação de instituições para formação e capacitação de militares, de órgãos de coordenação de atividades operacionais, além de estimular o surgimento de uma indústria nacional (ESCADA, 2005, p. 39). Nos últimos anos da Segunda Guerra, era patente a urgência de se empreender um programa de desenvolvimento científico e tecnológico no país. Objetivava-se fundar um centro técnico de pesquisas com a finalidade de desenvolver a tecnologia militar.

Em 1945, um grupo de oficiais da Força Aérea Brasileira (FAB) realizou algumas visitas a instituições norte-americanas de excelência e a bases aéreas. O objetivo da visita era conhecer centros de pesquisa que pudessem ajudar a desenvolver o modelo de uma instituição científica e tecnológica para o Brasil. Decidiu-se, 
então, que o centro técnico da Aeronáutica replicaria o modelo do Massachussets Institute of Tecnology (MIT), e o Brasil, inclusive, contaria com o apoio do chefe do departamento do referido instituto (ESCADA, 2005, p. 47).

Após meses discutindo o plano de criação de um centro técnico, em janeiro de 1946, foi aprovada a Comissão de Organização do Centro Técnico da Aeronáutica (COCTA). A Comissão foi extinta em 1953, quando cumpriu sua missão de executar o plano de institucionalização do Centro Técnico da Aeronáutica (CTA), que iniciou suas atividades no primeiro dia de 1954 em São José dos Campos, São Paulo. O CTA era uma instituição científica e técnica de pesquisa da Força Aérea Brasileira. Como centro de pesquisa, sua atribuição inicial era a de formação de cientistas para o desenvolvimento da tecnologia aeronáutica (COSTA FILHO, 2002, p. 69-69). Esse era o primeiro passo para superar as deficiências do poder aéreo brasileiro.

Nesse primeiro momento, o Brasil contou com a cooperação dos EUA parceiro militar desde 1940 - para a montagem da infraestrutura de apoio para o desenvolvimento de pesquisas ${ }^{6}$, além da colaboração do chefe do departamento de Aeronáutica do MIT, professor Richard H. Smith. Foram criados dois institutos científicos: o Instituto Tecnológico da Aeronáutica (ITA), voltado para a ensino superior qualificado; e o Instituto de Pesquisa e Desenvolvimento (IPD), que se concentrava na pesquisa e na cooperação com a indústria.

A criação do ITA, em 1948, foi um marco na formação de mão de obra especializada para o setor aeroespacial. No início, foram disponibilizados os cursos de engenharia aeronáutica de aeronaves, aerovias e eletrônica. O objetivo era suprir a demanda do mercado por recursos humanos qualificados, o que estava diretamente ligado ao desenvolvimento tecnológico do setor. Para compor o quadro de técnicos e professores - ainda indisponíveis no Brasil -, foi necessária a contratação no exterior, como nos Estados Unidos ${ }^{7}$ e Alemanha ${ }^{8}$.

Inicialmente, os engenheiros formados no ITA encontraram difícil inserção no mercado tecnológico brasileiro, devido à falta de um setor produtivo apto a

6 Segundo Costa Filho (2002), o Brasil comprou "equipamentos e material para os laboratórios de motores, estruturas, metalografia, resistência dos materiais e de máquinas e ferramentas, além de uma parte dos livros que iriam integrar o acervo da biblioteca do ITA".

7 Com a falta de técnicos e professores qualificados no Brasil, previa-se que a maioria dos professores seriam norte-americanos altamente capacitados, contratados por um período de quatro anos, renováveis por mais três. Após esse período, os norte-americanos seriam substituídos por brasileiros, preferencialmente os formados no instituto (ESCADA, 2005, p. 52).

8 Um dos nomes mais importantes é o do Prof. Henrich Focke, um dos fundadores da fábrica de aviões alemã Focke Wulf. Em 1951, o professor alemão mudou-se para o Brasil acompanhado de 20 técnicos de equipe (COSTA FILHO, 2002, p. 72-73). 
integrar a mão de obra altamente qualificada dos recém graduados no instituto. No entanto, esses engenheiros possibilitaram o abastecimento da nascente indústria bélica brasileira, localizada no Vale do Paraíba (COSTA FILHO, 2002, p. 73).

Após a completa consolidação do ITA, os esforços foram concentrados na instalação do segundo instituto científico previsto no plano do CTA: o Instituto de Pesquisa e Desenvolvimento (IPD). Em 1953, o Ministério da Aeronáutica, ciente da necessidade de se criar uma infraestrutura técnico-científica para apoiar o nascente parque industrial, criou o IPD. O novo instituto teria a função de investigar os entraves técnicos, econômicos e, principalmente, operacionais relacionados à Aeronáutica; cooperar com a nascente indústria de tecnologias; e examinar soluções adequadas às atividades da aviação nacional (ESCADA, 2005, p. 53). Em suma, o instituto seria responsável pelas pesquisas científicas e tecnológicas para impulsionar o desenvolvimento do setor no Brasil.

Nos primeiros anos do instituto, as atividades se concentraram no desenvolvimento de pesquisas de tecnologias para o setor aéreo. Com a coordenação dos professores e técnicos estrangeiros, foram desenvolvidos protótipos de novas aeronaves e helicópteros, como o Convertiplano ${ }^{9}$ e o Beija-Flor ${ }^{10}$. Posteriormente, as notícias vindas do exterior de que EUA e União Soviética (URSS) estavam a desenvolver satélites e os lançariam ao espaço entusiasmaram militares da Aeronáutica, além de alunos e professores dos dois institutos. Com isso, no final da década de 1950, iniciaram-se as primeiras pesquisas ligadas ao ramo espacial.

É importante ressaltar que o interesse pelo desenvolvimento científico e tecnológico no Brasil não se restringia à área aeroespacial. Personalidades, como o almirante Álvaro Alberto, foram grandes promotores da ciência e tecnologia de ponta no país. Nesse sentido, no início dos anos de 1950, concebeu-se a ideia de que era necessário criar uma instituição que impulsionasse as atividades científicas no Brasil, resultado natural do acompanhamento, por um grande número de cientistas brasileiros, do que vinha sendo desenvolvido no mundo. Assim, em 1951, foi criado o Conselho Nacional de Pesquisas (CNPq), um conselho de alto nível que trabalhava diretamente com a cúpula governamental para se criar uma política científica para o país (SATO, 2013, p. 819). A partir desse momento, os

9 O Convertiplano era um projeto de aeronave de decolagem vertical de autoria do professor Focke (ESCADA, 2005, p. 54).

10 O Beija-Flor era o projeto de um helicóptero para duas pessoas, também de autoria do professor Focke. O projeto tinha um desenvolvimento mais simples que o Convertiplano, razão pela qual se previa a sua industrialização (ESCADA, 2005, p. 54). 
desenvolvimentos científico e tecnológico do país transformavam-se em uma política de Estado.

Em 1957, a imprensa internacional divulgava, com bastante entusiasmo, que o Ano Geofísico Internacional (no ano seguinte, em 1958) seria dominado pelo lançamento de satélites artificiais por parte de russos e norte-americanos. No Brasil, dois estudantes de engenharia do ITA - Fernando de Mendonça e Júlio Alberto de Morais Coutinho -, contando com o apoio do presidente do IPD, o Coronel Aldo Weber Vieira da Rosa, tiveram a iniciativa de construir uma estação de rastreio dos satélites americanos do Projeto Vanguard. A estação foi batizada com o nome de Minitrack Mark II. Os satélites do projeto Vanguard estavam sendo desenvolvidos pelo Laboratório de Pesquisa Naval da Marinha dos EUA. Naquele momento, ainda se acreditava que os norte-americanos seriam os pioneiros na conquista espacial (ESCADA, 2005, p. 55; COSTA FILHO, 2002, p. 74).

Houve uma grande preparação para acompanhar o lançamento e funcionamento do primeiro satélite artificial, com a presença de pessoas e entidades militares e civis, da Aeronáutica e da Sociedade Interplanetária Brasileira (SIB). Os equipamentos necessários foram doados pelo governo norte-americano e todos ficaram à espera do grande acontecimento.

Entretanto, como é sabido, o primeiro satélite artificial do mundo foi produzido e lançado pela União Soviética, o Sputnik-I, em 4 de outubro de 1957, data em que se convencionou dizer que começou a Era Espacial (GOUVEIA, 2003, p. 3). Imediatamente, o grupo brasileiro realizou ajustes no sistema da estação e mudou a posição dos aparelhos, dirigindo-os para o satélite soviético. Consta que o acompanhamento foi feito com sucesso. Em janeiro de 1958, a estação também recebeu os dados do Explorer I, o primeiro satélite norte-americano a ser posto na órbita na Terra.

Esse grupo de pessoas e instituições inaugurou as atividades espaciais no Brasil. Com o sucessivo desenvolvimento da corrida espacial entre a União Soviética e os EUA, o grupo brasileiro só teve razões para manter e seguir adiante com o trabalho iniciado. Em 1959, Fernando de Mendonça, um dos estudantes de engenharia do ITA a construir a estação para receber dados do Sputnik I, foi fazer doutorado na Universidade de Stanford, nos EUA, e atuou em projetos da NASA, a Agência Espacial Norte-Americana ${ }^{11}$. Todavia, continuou atuando em

11 A NASA, sigla em inglês para National Aeronautics and Space Administration, é uma agência estatal dos Estados Unidos, responsável por implementar a política especial norte-americana. A agência foi criada em 1958, em substituição à NACA, National Advisory Committee for Aeronautics. 
estreita colaboração com o coronel Aldo Weber Vieira da Rosa para a criação de uma instituição voltada particularmente para a área espacial, que já vinha sendo discutida no seio da Aeronáutica e da Sociedade Interplanetária Brasileira (ESCADA, 2005, p. 56).

Nos primórdios dessa instituição está o Comitê Interamericano de Pesquisas Espaciais, criado após a realização da Reunião Interamericana de Pesquisas Espaciais, ocorrida em dezembro de 1960 na Argentina. Um dos objetivos desse comitê era estimular a criação de entidades governamentais voltadas exclusivamente para a área espacial nos países participantes. O presidente da SIB, Luiz de Gonzaga Bevilacqua, foi o participante brasileiro do Comitê e terá uma forte influência na criação da nova instituição brasileira, que tomará forma durante a gestão de Jânio Quadros (ESCADA, 2005, p. 56).

\section{A influência de Jânio Quadros e de sua Política Externa Independente na institucionalização das atividades espaciais no Brasil}

Jânio Quadros foi empossado como presidente da República no dia 31 de janeiro de 1961. Ele foi o presidente a inaugurar a institucionalização das atividades espaciais no Brasil, o que encontra razões em três fatores primordiais: a proximidade de Quadros com membros da SIB, que os permitiu exercerem influência direta sobre o presidente; a visita do russo Yuri Gagarin ao Brasil, primeiro ser humano a ir ao espaço; e, principalmente, seu comprometimento com o desenvolvimento das ciências no Brasil, que ultrapassava, até mesmo, os condicionantes ideológicos da Guerra Fria.

A conjunção de interesses em torno das questões espaciais, que unia estudantes do ITA, militares e associações, como a SIB, rendeu frutos, resultando na decisão de sensibilizar o presidente da República para as causas espaciais.

No dia 20 de fevereiro de 1961, Jânio Quadros recebeu do professor Luiz Gonzaga Bevilacqua, de quem era amigo pessoal (ESCADA, 2005, p. 47), uma carta assinada por ele e por Thomas Bun, ambos da SIB. Nessa carta, os dois sugeriam a criação de uma instituição voltada para as pesquisas espaciais no Brasil, afirmando que o país não podia ficar de fora dessas atividades. De acordo com Gatto (2010, p. 33), a carta deixava claro que "este seria o primeiro passo, a primeira manifestac „ão objetiva e pública do interesse do Governo do Brasil pelos problemas fascinantes da astronáutica, exatamente quando a humanidade se 
encontra no 40 ano da Era do Espac so”. Ao perceber a importância que Quadros havia dado a esse assunto, os militares da Aeronáutica juntaram-se aos civis no movimento em prol de uma entidade para fins puramente espaciais.

Segundo Santos (2005, p. 140), o presidente então enviou uma carta para o chefe da Casa Militar da Presidência da República, o general Ernesto Geisel, que convocou o coronel Aldo Weber Vieira da Rosa, do CTA, para tratar do assunto. Nas discussões entre os membros da SIB, a Aeronáutica e a Presidência da República foi sugerida a criação de uma instituição para cuidar da pesquisa espacial brasileira.

O tema ganhou ainda mais força após o feito inédito do russo Yuri Gagarin, que fez a primeira viagem pelo espaço, no dia 12 de abril de 1961. A imprensa brasileira noticiou o acontecimento em primeira página, esquecendo a tradicional rivalidade da Guerra Fria e concentrando-se em admirar a importância que esse fato significava para a humanidade ${ }^{12}$. O feito de Gagarin causou consternação no Brasil, sendo o primeiro cosmonauta classificado como "herói" em muitos meios.

A façanha extraordinária de Gagarin, que não encontrava precedentes até aquele momento, motivou o presidente Jânio Quadros a nomear, no dia 17 de maio de 1961, uma comissão composta por personalidades empenhadas no estabelecimento da instituição: coronel Aldo Weber Vieira da Rosa, diretor do CTA; almirante Otacílio Cunha, presidente do CNPq (Conselho Nacional de Pesquisas); e Luiz Gonzaga Bevilacqua e Thomas Bun, presidentes da SIB. No dia 15 do mês seguinte, a comissão encaminhou parecer com a sugestão de criar um Grupo de Organização da Comissão Nacional de Estudos Espaciais, que ficaria subordinado ao CNPq. A função dessa instituição seria de formar recursos humanos qualificados e desenvolver atividades nas áreas ligadas às ciências espaciais (ESCADA, 2005, p. 49).

A rapidez com que os ritos internos estavam sendo conduzidos para a institucionalização da entidade deixavam claro o entusiasmo de Jânio Quadros com as ciências espaciais. Motivado pelo frenesi do momento em torno dos grandes feitos na área, principalmente pelos dois maiores competidores, EUA e URSS, Jânio Quadros optou por não ficar de fora da corrida pela aquisição de tecnologia de ponta. Imbuído de um desejo de libertação da dependência tradicional com os norte-americanos, Quadros parecia querer afrontá-los e demonstrar que poderia seguir um rumo próprio. O presidente da República estava convicto que o Brasil

12 O Correio da Manhã do dia 13 de abril, por exemplo, enfatizava, em sua primeira página, a primeira frase dita pelo cosmonauta: “O céu é muito escuro e a Terra azulada”. Já o Estado de São Paulo do mesmo dia noticiava: "Astronauta soviético enviado ao espaço regressa depois de circundar a Terra: a humanidade entra na Idade Cósmica”. (CORREIO DA MANHÃ, 1961ª; ESTADO DE SÃO PAULO, 1961) 
era uma nação de grande relevância no jogo das potências mundiais e que, por isso, deveria demonstrar seu poderio e capacidade com o desenvolvimento interno das tecnologias espaciais.

Sabendo disso, o Instituto Brasileiro de Astronáutica e Ciências Espaciais (IBACE), sediado em SP, enviou uma carta ao presidente da República sugerindo convidar o cosmonauta Yuri Gagarin para uma visita ao país (CORREIO DA MANHÃ, 1961b, 1961e; FOLHA DE SÃO PAULO, 1961a, 1961b, 1961e). Dois dias depois, a imprensa brasileira noticiou que Jânio Quadros animou-se com a ideia e estava disposto a convidar Yuri Gagarin para vir ao Brasil na qualidade de hóspede oficial do governo (CORREIO DA MANHÃ, 1961c). De fato, a viagem de Gagarin representava o atendimento de um desejo pessoal do presidente da República, manifestado, também, durante seu encontro com a Missão Soviética da Boa-Vontade (JORNAL DO BRASIL, 1961a). Posteriormente, o prof. Flávio A. Pereira, do IBACE, dirigiu a carta-convite ao Comitê de Estado soviético ${ }^{13}$.

A visita de Gagarin ocorreu entre os dias 29 de julho e 2 de agosto de 1961, após sua passagem por Londres ${ }^{14}$, Varsóvia e Havana, locais onde o cosmonauta foi ovacionado durante sua estada. Durante os preparativos para a recepção do soviético, Jânio Quadros determinou ao Itamaraty e a entidades científicas que recebessem o astronauta e promovessem palestras e conferências, o que julgava de grande importância para a ciência brasileira. "Parece-me do mais alto interesse para os nossos meios científicos palestras e conferências desse astronauta”, afirmou Quadros em memorando presidencial dirigido aos ministros da Educação e da Aeronáutica e ao Conselho Nacional de Pesquisas (ÚLTIMA HORA, 1961a).

Gagarin desembarcou no Rio de Janeiro no dia 29 de julho, onde foi recebido com honras militares pelo almirante Otacílio Cunha, presidente do CNPq, e outras personalidades militares. A chegada de Gagarin foi marcada por aglomerações,

13 Texto integral do convite reproduzido na primeira página pela Folha de São Paulo do dia 28 de julho de 1961 com o seguinte teor: "Tenho a honra de convidar o major Yuri Gagarin para visitar o Brasil e aqui proferir uma conferência sobre a memorável viagem orbital que realizou em 12 de abril de 1961 a bordo da cosmonave Vostok. Faço esse convite na qualidade de diretor-presidente do Instituto Brasileiro de Astronáutica e Ciências Espaciais, de São Paulo. Tomo a liberdade de formular o anteprojeto de programa da visita do comandante Gagarin, no qual está incluído um encontro no Palácio do Planalto com o Sr. Presidente da República, Dr. Jânio Quadros. A aceitação do convite poderia ser feita através do Instituto União Cultural Brasil-URSS, de São Paulo"(FOLHA DE SÃO PAULO, 1961c).

14 "Em sua chegada a Londres, Gagarin foi recepcionado com muitos aplausos em um trajeto de cerca de $24 \mathrm{Km}$. Na Exposição Comercial Soviética, mais de mil pessoas rodearam o cosmonauta, causando tumulto e desconforto para o russo. As proporções da manifestação se tornaram superiores às possibilidades dos guardas para protegêlo. Algumas mulheres desmaiaram, as crianças tiveram que ser carregadas por seus pais para evitar que fossem pisoteadas. Houve gritos de pânico”. Relato da visita a Londres pelo Jornal do Brasil do dia 12 de julho de 1961. 
tumulto e violência contra a imprensa (FOLHA DE SÃO PAULO, 1961e). Jânio Quadros, que estava em viagem a São Luiz, no Maranhão, para a VI Reunião de Governadores, revelou em entrevista que considerava a visita de Yuri Gagarin "da mais significativa importância para o Brasil" e que "não tinha dúvidas que suas palestras seriam de grande utilidade para todos, pois rasgou estradas e universos, ensejando horizontes para o homem" (JORNAL DO BRASIL, 1961b).

Dada a importância que as ciências haviam alcançado no Brasil, uma das programações no Rio de Janeiro incluía visita à Academia Brasileira de Ciências, no dia 30 de julho. Ali, Gagarin foi recebido pelo almirante Otacílio Cunha e Arthur Moses, presidente da Academia Brasileira de Ciências, onde permaneceu por uma hora, respondendo a perguntas de cientistas interessados na aventura do soviético no espaço.

No dia seguinte, em São Paulo, foi recebido pelo governador Carvalho Pinto, que concedeu ao astronauta o diploma de Sócio Honorário da SIB. O presidente da SIB, Thomas Bun, entregou-lhe também uma carta, endereçada à Academia de Ciências da URSS, objetivando o estreitamento do intercâmbio científico entre as entidades dos responsáveis pelas pesquisas espaciais dos dois países. Posteriormente, Gagarin proferiu uma conferência no Instituto Municipal de Astrofísica de São Paulo (JORNAL DO BRASIL, 1961c; FOLHA DE SÃO PAULO, 1961d).

O último dia de sua visita foi reservado para o encontro com o presidente da República em Brasília. Em solenidade no Palácio do Planalto, Gagarin foi condecorado com o grau de Comendador da Ordem do Mérito Aeronáutico pelo presidente Jânio Quadros, em uma homenagem que contou com a presença de todos os funcionários do Palácio ${ }^{15}$ (CORREIO DA MANHÃ, 1961d).

$\mathrm{O}$ astronauta soviético agradeceu ao presidente e entregou-lhe uma mensagem pessoal de Nikita Kruschev, que agradecia a recepção de seu astronauta. Kruschev revelou que considerava o convite a Gagarin "uma manifestação dos sentimentos amistosos do povo do Brasil aos povos da URSS". A mensagem de Kruschev demonstrava o tom cordial da URSS para com o Brasil, resultado das já intensas conversações entre os dois países a respeito do reatamento das relações diplomáticas, que já vinha desde o início do governo Jânio Quadros. Essa era uma das plataformas de Jânio para ampliar a cooperação comercial, científica e tecnológica brasileira

15 Ao conceder a Comenda, Quadros disse que "homenageava o pioneiro de uma era que permitirá maior entendimento entre os homens e a consolidação da paz [...] o Governo Brasileiro deseja exprimir a sua admiração e o seu reconhecimento pelo extraordinário feito científico que tanto notabilizou V. Excelência, o povo e o governo soviético". 
com o mundo. Apesar de todo o esforço e entusiasmo de Jânio Quadros e Afonso Arinos, o reatamento só foi consolidado durante a presidência de João Goulart, no dia 23 de novembro de 1961.

Os EUA acompanharam a visita de Gagarin ao Brasil com grande atenção. O interesse de Jânio Quadros pelo desenvolvimento das ciências espaciais no Brasil já havia sido comunicado aos estadunidenses. Como visto anteriormente, grandes cientistas brasileiros viviam nos EUA e executavam projetos nos institutos de pesquisa americanos, muito em função da carência de centros de pesquisa científicos no país. Temendo que os brasileiros estabelecessem acordos diretos com os soviéticos nesse campo, Jânio recebeu um relatório dos EUA propondo uma cooperação com o uso dos foguetes norte-americanos pouco antes do presidente receber Gagarin no Palácio do Planalto (ÚLTIMA HORA, 1961b). Esse ato simbolizou a preocupação dos EUA com uma eventual aproximação do Brasil com seu principal adversário, a URSS, na área em que se encontravam mais adiantados que os americanos, a espacial. A rapidez e efetividade com que Quadros conduziu o processo de institucionalização era um demonstrativo do desejo de obter independência nessa seara, vital para o progresso de uma nação.

A importância que Jânio Quadros atribuía ao desenvolvimento das ciências espaciais no Brasil, que se expandiu devido ao enorme sucesso provocado pela passagem de Gagarin, comprovou-se com a assinatura do decreto criando o GOCNAE, o Grupo de Organização da Comissão Nacional de Atividades Espaciais, no dia 3 de agosto de 1961, dia seguinte ao retorno do astronauta à URSS. O Decreto 51.133/1961 (BRASIL, 1961) estabelecia suas atribuições, seus objetivos, a composição de seus membros e dava outras providências.

Entre suas atribuições, estava: estudar e compor a Política Espacial Brasileira; preparar o plano de criação da Comissão Nacional das Atividades Espaciais; executar projetos de pesquisas espaciais; firmar acordos relacionados à instalação da sede; gerir as obras e serviços indispensáveis à criação do CNAE (BRASIL, 1961). Em suma, eram dois objetivos: promover a pesquisa espacial civil e coordenar as atividades espaciais (COSTA FILHO, 2002, p. 82).

A primeira composição do GOCNAE foi representada por renomadas personalidades do meio militar e civil já comprometidos com as ciências espaciais: o presidente era o coronel Aldo Weber Vieira da Rosa (Aeronáutica); o Comitê Executivo era composto pelo coronel Alnyr Maurício (Exército), almirante Botelho Machado (Marinha) e coronel Sérgio Sobral de Oliveira (Aeronáutica); o conselho era composto por Luiz Gonzaga Bevilacqua (presidente honorário da SIB), Thomas 
Bun (presidente da SIB) e Lincoln Eduardo de Souza Bittencourt, todos civis e representantes da SIB (ESCADA, 2005, 49).

O alvoroço em torno da renúncia de Jânio Quadros (apenas 22 dias após o decreto de criação do GOCNAE) e da posse do vice, João Goulart, refletiu no início das atividades da organização, que só teve seus membros empossados no dia 22 de janeiro de 1962, seis meses após a publicação do decreto (JORNAL DO BRASIL, 1962). O grupo se reunia no terceiro andar do Aeroporto de Congonhas, em São Paulo, local com acesso facilitado para todos os membros, que se deslocavam de avião de diferentes cidades, como Bauru, São José dos Campos e Rio de Janeiro. Em 45 dias, foi elaborado um documento delineando a trajetória que o Brasil deveria seguir, a começar pela criação da Comissão Nacional de Atividades Espaciais (CNAE) (DA ROSA, 2007).

No plano inicial de trabalho, as áreas prioritárias foram definidas como astronomia, radioastronomia, rastreio ótico de satélites e comunicação por meio de satélites. Como observado por Costa Filho (2002, p. 83), o plano inicial de pesquisas espaciais voltava-se para estudos da ionosfera, geomagnetismo e meteorologia, refletindo projetos já em curso na NASA.

Em função da situação política e econômica do país, houve dificuldade inicial em captar recursos para a institucionalização da entidade. De acordo com informações divulgadas no Última Hora de 19 de fevereiro de 1961, o grupo não dispunha de dinheiro para começar suas pesquisas. "O GOCNAE pediu a abertura de um crédito extraordinário de 50 milhões de cruzeiros e não foi atendido por empecilhos administrativos", afirmou a matéria (ÚLTIMA HORA, 1961c). Os obstáculos iniciais também impediram a criação da CNAE de imediato, como proposto pelo coronel Aldo Weber. Seguiu-se um período de intensa dedicação para persuadir o sucessor, João Goulart, a efetivamente instituir a criação da CNAE (DA ROSA, 2007).

Consequentemente, o CNAE só conseguiu iniciar suas atividades em 1963, em São José dos Campos, dentro das instalações do CTA. O GOCNAE tornou-se CNAE, de fato, em 1964, após o golpe militar. Ele foi extinto em 1971, quando foi substituído pelo Instituto Nacional de Pesquisas Espaciais, o INPE16, o principal órgão de pesquisas civis da área espacial até os dias de hoje. O INPE é a instituição brasileira responsável por promover e efetivar estudos, pesquisas, desenvolvimento tecnológico e capacitar recursos humanos em áreas relacionadas

16 O Decreto n. 68.532 de 22 de abril de 1971 extingue o GOCNAE e cria o Instituto de Pesquisas Espaciais (INPE). 
à ciência espacial, como atmosfera e meteorologia. O foco do INPE é desenvolver a ciência e a tecnologia espacial internamente, considerando que suas aplicações influenciam diretamente no desenvolvimento do país e na qualidade de vida da população brasileira.

\section{Conclusões}

Jânio Quadros utilizava a política externa como ferramenta a serviço da resolução de problemas internos. Um dos principais gargalos que impediam o país de alcançar uma posição de destaque entre as grandes potências era seu modesto desenvolvimento científico e tecnológico. Entusiasmado com as conquistas espaciais recentes dos EUA e URSS e sendo fortemente aconselhado por um grupo de civis e militares brasileiros determinados a desenvolverem as tecnologias espaciais internamente, Jânio Quadros, em um período de seis meses, fez o que os seus antecessores não fizeram: articulou e executou a criação do primeiro órgão responsável por pesquisas e desenvolvimento da tecnologia espacial no Brasil, o GOCNAE.

Três foram os motivadores principais para a decisão de Jânio Quadros de impulsionar as atividades espaciais no Brasil: seu relacionamento pessoal com membros da SIB, que tinham acesso direto ao presidente; a visita do astronauta russo Yuri Gagarin ao Brasil, estimulada pelo próprio Jânio; e, principalmente, seu comprometimento com o progresso das ciências no Brasil, que ultrapassava, até mesmo, os condicionantes ideológicos da Guerra Fria.

Nada disso seria possível, contudo, sem a existência de um novo paradigma de política externa na gestão de Quadros. A constituição de uma política externa arrojada e pragmática, que se amparava na desideologização, no neutralismo, ou seja, no estabelecimento de parcerias sem preconceitos ideológicos, foi a outorga necessária para se levar adiante o plano de iniciar as atividades espaciais no Brasil de forma institucionalizada. A PEI foi o início de um processo de afastamento do americanismo puro, um paradigma de política externa que vinha desde o início da República, que inibia a tomada de decisões mais autônomas do Brasil que não se coadunassem com os interesses dos EUA.

Quadros, em seu artigo publicado na revista Foreign Affairs, deixou clara a sua insatisfação com o jogo que as grandes potências ainda faziam com o Brasil. A nova política externa era uma tentativa de diminuir a forte dependência brasileira, 
para, assim, corrigir os inúmeros desequilíbrios socioeconômicos existentes no Brasil. Quadros acreditava que alçar o Brasil à condição de detentor de tecnologias espaciais traria desenvolvimento econômico e destaque internacional para o país.

Apesar da curta duração de sua administração, Jânio Quadros será permanentemente relacionado à inauguração de uma nova vertente de política externa, a PEI, que ampliou as possibilidades de atuação internacional do país e permitiu o desenvolvimento de uma agenda doméstica relativamente livre dos condicionamentos externos. No ramo espacial, a figura de Quadros também se associa à criação da primeira instituição dedicada às atividades espaciais. A sua influência direta no desenvolvimento do GOCNAE permite que se atribua ao Brasil o título de um dos primeiros países em desenvolvimento a investir em pesquisas de tecnologias exclusivamente espaciais. Nessa época, apenas China e Índia estavam no mesmo estágio.

Não obstante o grande impulso dado pelo país com a institucionalização do GOCNAE - que, dez anos depois, se tornou INPE, uma das mais dedicadas e conceituadas instituições científicas brasileiras da atualidade -, o programa espacial brasileiro enfrentou um lento processo de desenvolvimento. Com a transferência de tecnologia da URSS, indianos e chineses souberam desenvolver seus programas espaciais em um curto período. Em 1965, a China já lançava seu primeiro foguete e, cinco anos depois, já conseguia colocar um satélite em órbita (RODRIGUES, 2015, p. 1).

Enquanto isso, no Brasil, o foco girava em torno de adquirir a tecnologia de satélites e foguetes a partir de projetos ainda pouco ambiciosos e com auxílio internacional, em especial da França, parceira na elaboração da Missão Espacial Completa Brasileira (MECB), estabelecida em 1979, e também dos EUA, através do projeto SONDA, de desenvolvimento de foguetes de pequeno porte para serem utilizados em experimentos na atmosfera (CARVALHO, 2011, p. 18; RODRIGUES, 2015, p. 1; COSTA FILHO, 2002, p. 78).

Nesse início, o caráter essencialmente militar dos projetos foi responsável pelo excesso de lentidão no andamento das atividades e pelo afastamento das parcerias internacionais, que temiam o uso não pacífico das tecnologias de mísseis. Foi somente em 1994, com a criação da Agência Espacial Brasileira (AEB), que o programa espacial passou a ter uma finalidade civil, o que, no entanto, não afastou a suspeita de alguns países quanto ao componente militar de suas atividades (SANTOS, 1999, p. 118; RODRIGUES, 2015, p. 2). 
Contudo, enquanto os programas espaciais de países emergentes como China, Índia e Argentina vêm avançando de forma acelerada, o programa brasileiro perde o destaque que obteve por ter sido um dos mais antigos e completos. Hoje, ele caminha em passos lentos, apesar de anos de dedicação de diversos cientistas e técnicos. Entre as justificativas para a lentidão no progresso tecnologia espacial no Brasil, estão o orçamento limitado destinado aos projetos e pesquisas; os embargos internacionais; as dificuldades operacionais e a cooperação internacional verticalizada que não foi acompanhada de resultados na evolução do Programa Espacial (ROLLEMBERG, 2009, p. 4, 27, 34-35).

\section{Referências}

ÁLVARES, Vera Cíntia. Reflexões sobre o surgimento da "Política Externa Independente” na gestão de Jânio Quadros. In: Ensaios de História Diplomática do Brasil (1930-1986) - Cadernos do IPRI n. 2. Brasília: Fundação Alexandre de Gusmão, 1989.

BRASIL. Decreto n. 51.133 de 3 de Agosto de 1961. Cria o Grupo da Comissão Nacional de Atividades Espaciais e dá outras providências. Disponível em: < http://www2. camara.leg.br/legin/fed/decret/1960-1969/decreto-51133-3-agosto-1961-390741publicacaooriginal-1-pe.html > . Acesso em: 1 Nov 2016.

CARVALHO, Himilcon de Castro. Alternativas de financiamento e parcerias internacionais estratégicas no setor espacial. In: FREITAS, W. L. de. (coord.). Desafios do Programa Espacial Brasileiro. Brasília: Presidência da República - Secretaria de Assuntos Estratégicos, 2011. p. 17-40. Disponível em: < http://www.sae.gov.br/wp-content/ uploads/espacial_site.pdf >. Acesso em: 1 Nov 2016.

CERVO, Amado Luiz; BUENO, Clodoaldo. História da Política Exterior do Brasil. 3a ed. Brasília: Editora Universidade de Brasília, 2010.

CERVO, Amado Luiz. Eixos conceituais da política exterior do Brasil. In: Revista Brasileira de Política Internacional. V. 41, N. spe. Brasília, 1998. Disponível em: http://www. scielo.br/scielo.php?script = sci_arttext\&pid = S0034-73291998000300005 Acesso em: 01 Nov 2016.

COSTA FILHO, Edmilson. Política Espacial Brasileira: A política científica e tecnológica no setor aeroespacial brasileiro. Rio de Janeiro: Revan, 2002.

CORREIO DA MANHÃ. O céu é muito escuro e a Terra azulada. Rio de Janeiro: 13.04.1961. Primeira página. 1961a. Disponível em: < http://memoria.bn.br/hdb/uf.aspx > . Acesso em: 04 Nov 2016.

CORREIO DA MANHÃ. A notícia dia a dia. Rio de Janeiro: 16.07.1961. 1961b. Disponível em: < http://memoria.bn.br/hdb/uf.aspx > . Acesso em: 04 Nov 2016. 
CORREIO DA MANHÃ. A notícia dia a dia. Rio de Janeiro: 18.07.1961. 1961c. Disponível em: < http://memoria.bn.br/hdb/uf.aspx > . Acesso em: 04 Nov 2016.

CORREIO DA MANHÃ. Gagarin recebe comenda do Mérito Aeronáutico. Rio de Janeiro: 3.08.1961. 1961d. Disponível em: < http://memoria.bn.br/hdb/uf.aspx > Acesso em: 04 Nov 2016.

CORREIO DA MANHÃ. Gagarin convidado a visitar SP. Rio de Janeiro: 22.07.1961. 1961e. Disponível em: < http://memoria.bn.br/hdb/uf.aspx > . Acesso em: 04 Nov 2016.

DA ROSA, Aldo Weber Vieira. Entrevista concedida ao ex-diretor do SindCT (Sindicato dos Servidores de Ciência e Tecnologia), em 2007. Disponível em: http://www. sindct.org.br/?q = node/29. Acesso em 04 Nov 2016.

ESCADA, Paulo Augusto Sobral. Origem, institucionalização e desenvolvimento das atividades espaciais brasileiras (1940-1980). 2005. 129f. Dissertação (Mestrado em Ciência Política) - Instituto de Filosofia e Ciências Humanas (IFCH), Universidade Estadual de Campinas. Campinas, 2005.

ESTADO DE SÃO PAULO. Astronauta soviético enviado ao espaço regressa depois de circundar a Terra: a humanidade entra na Idade Cósmica. São Paulo: 13.04.1961. Disponível em: < http://memoria.bn.br/hdb/uf.aspx > . Acesso em: 03 Nov 2016. FOLHA DE SÃO PAULO. Gagarin recebe convite para vir a São Paulo. São Paulo: 21.07.1961. 1961a. Disponível em: < http://acervo.folha.uol.com.br/fsp/1961/07/21/2//4487549 > . Acesso em: 03 Nov 2016.

FOLHA DE SÃO PAULO. Gagarin, "honrado" com o convite, chega ao Brasil depois de amanhã. São Paulo: 27.07.1961. Primeiro Caderno. 1961b. Disponível em: < http:// acervo.folha.uol.com.br/fsp/1961/07/27/2//4488014 > . Acesso em: 03 Nov 2016.

FOLHA DE SÃO PAULO. Esperado amanhã no Rio o cosmonauta Gagarin. São Paulo: 28.07.1961. 1961c. Disponível em: < http://acervo.folha.uol.com.br/ fsp/1961/07/28/2//4488087 > . Acesso em: 03 Nov 2016.

FOLHA DE SÃO PAULO. Gagarin fez conferência, almoçou com jornalistas e falou com governador. São Paulo: 2.08.1961. 1961d. Disponível em: < http://acervo.folha.uol. com.br/fsp/1961/08/02/2//4488563 > . Acesso em: 03 Nov 2016.

FOLHA DE SÃO PAULO. Entusiasmo à chegada de Gagarin a Brasília; violência contra a imprensa. São Paulo: 30.07.1961, p. 13. 1961e. Disponível em: < http://acervo. folha.uol.com.br/fsp/1961/07/30/2//4488183 > . Acesso em: 03 Nov 2016.

FRANCO, Álvaro da Costa (Org.). Documentos da Política Externa Independente. Brasília: Fundação Alexandre de Gusmão, 2007.

GATTO, Rubens Cruz. A inovação e o setor público no Brasil: o papel do Estado no desenvolvimento das atividades espaciais no INPE. 2010. 47f. Trabalho de Conclusão de Curso (MBA em Gestão Estratégica da Ciência e Tecnologia em Instituições Públicas de Pesquisa) - Fundação Getúlio Vargas. São José dos Campos: 2010. 
GOUVEIA, Adalton. Esboço histórico da pesquisa espacial no Brasil. Instituto Nacional de Pesquisas Espaciais - INPE. São José dos Campos: 2003.

JORNAL DO BRASIL. Gagarin chega sábado ao Rio, anuncia Arinos em Brasília. São Paulo: 27.07.1961. 1961a. Disponível em: < http://memoria.bn.br/hdb/uf.aspx > . Acesso em: 03 Nov 2016.

JORNAL DO BRASIL. Gagarin chega ao Brasil com honras militares e tumulto. Rio de Janeiro: 30.07.1961. Primeiro Caderno, p. 04. 1961b. Disponível em: < http://memoria.bn.br/hdb/uf.aspx > . Acesso em: 03 Nov 2016.

JORNAL DO BRASIL. Gagarin diz que o Brasil pode contribuir nas pesquisas astronáuticas. Rio de Janeiro: 2.08.1961. 1961c. Disponível em: < http://memoria.bn.br/hdb/ uf.aspx > . Acesso em: 03 Nov 2016.

JORNAL DO BRASIL. Toma posse grupo que vai estudar o espaço e começa soltando foguetes. Rio de Janeiro: 23.01.1962. Disponível em: < http://memoria.bn.br/hdb/ uf.aspx > . Acesso em: 04 Nov 2016.

QUADROS, Jânio. Nova Política Externa do Brasil. In: Revista Brasileira de Política Internacional. Ano IV, n. 16, dez 1961.

RODRIGUES, Alexandre. Qual é o problema do programa espacial brasileiro? Galileu. 07 Jan 2015. Disponível em: < http://revistagalileu.globo.com/Revista/noticia/2015/01/ nos-temos-um-problema.html > . Acesso em: 1 Nov 2016.

ROllemberG, Rodrigo. Cenário e perspectivas da Política Espacial Brasileira. In: ROLLEMBERG, Rodrigo (relator); VELOSO, Elizabeth Machado (coord.). A Política Espacial Brasileira. Brasília: Câmara dos Deputados, 2009. Série Caderno de Altos Estudos N. 7. p. 19-84. Disponível em: < http://www2.camara.leg.br/a-camara/ altosestudos/arquivos/politica-espacial/a-politica-espacial-brasileira > . Acesso em: 1 Nov 2016.

SANTOS, Reginaldo. O Programa Nacional de Atividades Espaciais frente aos embargos tecnológicos. Parcerias Estratégicas. Vol. 4, N. 07, CGEE/MCT, Outubro/1999, p. 115-128. Disponível em: < http://www.cgee.org.br/arquivos/pe_07.pdf > . Acesso em: 1 Nov 2016.

SANTOS, Paulo Marques dos. Instituto Astronômico e Geofísico da USP: memória sobre a sua formação e evolução. São Paulo: Editora USP, 2005.

SATO, Eiiti. Almirante Álvaro Alberto: a busca do desenvolvimento científico e tecnológico nacional. In: PIMENTEL, José Vicente de Sá. Pensamento Diplomático Brasileiro: formuladores e agentes da política externa (1750-1964). Vol. III, Brasília, Funag, 2013, p. 801-842.

ÚlTiMA HORA. Gagarin sábado no Rio a convite de Jânio. P. 04. Rio de Janeiro: 27.07.1961. 1961a. Disponível em: < http://memoria.bn.br/hdb/uf.aspx > . Acesso em: 03 Nov 2016. 
ÚLTIMA HORA. Jânio estuda (com cuidado) foguetes ianques no Brasil. Rio de Janeiro: 4.08.1961. 1961b. Disponível em: < http://memoria.bn.br/hdb/uf.aspx > . Acesso em: 04 Nov 2016.

ÚlTIMA HORA. Pesquisas espaciais. Rio de Janeiro: 19.02.1961. 1961c. Disponível em: < http://memoria.bn.br/hdb/uf.aspx > . Acesso em: 03 Nov 2016.

VISENTINI, Paulo Fagundes. Relações Exteriores do Brasil II (1930-1964): o nacionalismo, da Era Vargas à Política Externa Independente. Coleção Relações Internacionais. 2a ed. Petrópolis, RJ: Editora Vozes, 2009.

WROBEL, Paulo S. Aspectos da Política Externa Independente: a questão do desarmamento e o caso de Cuba. Estudos Históricos. Rio de Janeiro, Vol. 6, n. 12, 1993, p. 191-209. 